\title{
Attitudes towards Death, Perceptions of Hospice Care, and Hospice Care Needs among Family Members of Patients in the Intensive Care Unit
}

\author{
Yunha Oak, R.N. and Young-Sun Kim, R.N., Ph.D.* \\ Department of Nursing, Dong-A University Hospital, "Department of Nursing, College of Nursing, \\ Catholic University of Pusan, Busan, Korea
}

Purpose: This study aimed to identify the relationships among attitudes towards death, perceptions of hospice care, and hospice care needs as perceived by family members of patients in the intensive care unit (ICU). Methods: This study used a descriptive correlational method. A structured questionnaire was used to collect data from 114 participating families in the ICU at Dong-A University Hospital, from October 10 to November 1, 2019. The data were analyzed in terms of frequency, percentage, and mean and standard deviation. The t-test, one-way analysis of variance, and Pearson correlation coefficients were also conducted. Results: Perceptions of hospice care showed significant differences according to age $(\mathrm{F}=3.06, \mathrm{P}=0.031)$ and marital status $(\mathrm{t}=3.55, \mathrm{P}=0.001)$. However, no significant differences in attitudes towards death or hospice care needs were found. A significant positive correlation was found between perceptions of hospice care and hospice care needs $(r=0.49$, $\mathrm{P}<0.001$ ). Conclusion: In order for families to recognize the need for hospice care and to receive high-quality palliative care at the appropriate time, it is necessary to increase public awareness of hospice care through various educational and awareness-raising efforts, thereby providing opportunities for families of terminally ill patients to request hospice care.

Key Words: Intensive care units, Family, Hospice care, Death
Received March 10, 2020

Revised June 23, 2020

Accepted August 14, 2020

\section{Correspondence to}

Young-Sun Kim

ORCID:

https://orcid.org/0000-0001-6408-9516

E-mail:yskim0821@cup.ac.kr

This article is based on the 2020 master's thesis by the first author, Yunha Oak.

\section{INTRODUCTION}

\section{Background}

The intensive care unit (ICU) is the culmination of advances in modern medicine and is a place where many patients $\mathrm{re}^{-}$ ceive life-saving treatment. However, the development of medical technology has resulted in meaningless life-sustaining treatment that requires life-support equipment even if curative treatment of the disease is not possible [1]. Futile lifesustaining treatment causes pain for patients and their family members and diminishes patients' dignity and value. Therefore, to improve the quality of life among patients facing lifethreatening diseases and their family members, the ICU is becoming an important location for the provision of hospice and palliative care [2].

Providing hospice and palliative care to patients in the ICU leads to benefits such as a reduced duration of stay in the ICU and/or hospital; fewer futile treatments; shorter mechanical ventilation; increased satisfaction and understanding among the patient's family members; reduced anxiety, depression, and post-traumatic stress among the patient's family members; 
and reduced conflict with the medical staff [3]. Most patients in the ICU have serious symptoms due to life-threatening damage to their physiological systems and/or rapid changes in status, and many are unconscious and rely on artificial machines such as ventilators; therefore, it is difficult for ICU patients to participate in the decision-making process for their own care. In South Korea, close bonds exist among family members, and most decisions on behalf of the patient are made by family members [4]. Therefore, the values and opinions of patients' family members play a very important role in deciding on the treatment direction. The role of family is especially important in the ICU, where the patient's ability to communicate is compromised [5].

Family members of patients in the ICU experience painful emotions, such as guilt, anger, and uncertainty related to treatment, when treatment and recovery are delayed after patients are admitted to the ICU. Such emotional pain exacerbates their anxiety and fear toward death and can lead to negative attitudes toward death [6]. Attitudes toward death refer to one's personal beliefs about death, which are influenced by sociocultural, religious, and philosophical frameworks, as well as belief systems and personal cognition. As such, attitudes toward death are a multidimensional concept shaped by many elements, including meaning, understanding, fear and apprehension, and anxiety regarding death [7]. Therefore, an individual's attitude toward death not only influences his or her quality of life, but is also an important aspect in making decisions about treatment in a crisis situation such as a family member's admission to the ICU [6].

In order to request hospice and palliative care, it is important to have a proper understanding of the relevant concepts. Hospice and palliative care helps patients whose death is predicted and their family members to maintain human dignity and quality of life and to enjoy rich and peaceful lives until death. Hospice and palliative care has recently been acknowledged as an important consideration in caring for ICU patients with complex and severe diseases [2]. Therefore, for hospice and palliative care to be provided at an appropriate time during the ICU stay, it is necessary to understand the level of awareness of hospice and palliative care among patients' family members, who function as decision makers in the ICU, as well as to obtain insights into related factors.
More than $40 \%$ of patients in the ICU experience severe pain and difficulty breathing 3 days before death, and family members also face many difficulties due to the complex and severe diseases experienced by patients [8]. This situation is an important contributor to hospice and palliative nursing needs, which refer to requests made by patients and their family members to nurses after recognizing the need for efficient and high-quality palliative care. Therefore, even more than other areas of nursing, hospice and palliative nursing care should be family-oriented, and needs should be assessed based on input from family members.

Previous studies on attitudes toward death and on awareness and needs for hospice and palliative care include a study conducted among cancer patients and their family members [9]. However, that study provides a limited understanding of the impact of attitudes toward death and awareness of hospice and palliative care on nursing needs among family members of patients in the ICU, many of whom have life-threatening diseases other than cancer. Research on hospice and palliative care in the ICU has been actively conducted internationally in recent years [10-12], and researchers have also addressed the needs and perceptions of family members [13]. However, research on hospice and palliative care in South Korea is relatively limited, and studies conducted among family members are also lacking.

Therefore, this study aimed to provide a foundation for the delivery of high-quality hospice and palliative care in the ICU at an appropriate time by investigating the relationships among attitudes toward death, perceptions of hospice care, and hospice care needs as perceived by family members of ICU patients, who are the decision-making entities in the ICU setting.

\section{Purpose}

This study investigated the relationships among attitudes toward death, perceptions of hospice care, and hospice care needs. Its specific goals were as follows:

A. To identify attitudes toward death, perceptions of hospice care, and hospice care needs among family members of $\mathrm{pa}^{-}$ tients in the ICU.

B. To determine differences in attitudes toward death, perceptions of hospice care, and hospice care needs according to participants' general characteristics. 
C. To explore associations among attitudes toward death, perceptions of hospice care, and hospice care needs.

\section{METHODS}

\section{Study participants and data collection}

The participants in this study were adults who were 18 years of age and above, who could communicate fluently, and who were family members of patients receiving treatment in the Dong-A University Hospital ICU in Busan. Spouses, children, grandchildren, and siblings who were aware of the diagnosis and status of the patient in the ICU were included, but family members who were only visiting were excluded. Data were collected from October 10, 2019 to November 1, 2019.

The sample size for this study was calculated using G*Power version 3.1.9.2. The minimum sample size with a significance level $(\alpha)$ of 0.05 , power $(1-\beta)$ of 0.80 , and effect size $(r)$ of 0.30 was 111 . Considering a $20 \%$ dropout rate, 133 surveys were distributed. All 133 surveys were returned, but 114 surveys were used in the final analysis after excluding 19 with unclear or omitted answers.

Data collection was conducted after receiving approval from Catholic University of Pusan Institutional Review Board (CUPIRB-2019-054) and consent from the departments of intensive care and nursing in the Dong-A University Hospital in Busan. A recruitment poster was created and posted in the corridors in front of the ICU and in the ICU waiting rooms before, during, and after ICU visitation hours. The researcher explained the study to individuals who expressed interest and received written consent before handing out the survey for participants to complete. It was explained that the survey was to be completed once during the study period. Although in principle participants completed the survey on their own, if the participants had poor eyesight or if the participants requested, the researcher read the questions out loud and recorded the answers.

\section{Research tools}

The structured, self-report survey used in this study comprised 77 items in total, with nine items on general characteristics, 25 items on attitudes toward death, 20 items on percep- tions of hospice care, and 23 items on hospice care needs.

\section{1) Attitudes toward death}

A tool developed by Thorson and Powell [7], translated by Park [14], and revised and updated by Yoo [15] was used.

This tool consisted of a total of 25 items, with 16 items worded positively and nine items negatively. Each item was measured using a 4-point Likert scale from "strongly agree" (1 point) to "rarely" (4 points). Higher scores indicated more positive attitudes toward death.

Cronbach's $\alpha$ for the original tool was 0.83 , while it was 0.84 in the study of Yoo [15]. In this study, Cronbach's $\alpha$ was 0.87 .

\section{2) Perceptions of hospice care}

A tool developed by Kim [16] and Lee [17] and revised and updated by Gwak [18] was used.

This tool consisted of 20 items in five areas: four items for definitions and philosophy, two items on recipients of care, eight items on care services, four items on psychology and ethics, and two items on the need for awareness-raising and education. Each item was rated on a 4-point Likert scale, from "strongly agree" (4 points) to "rarely" (1 point). Higher scores indicated higher levels of perception of hospice care.

Cronbach's $\alpha$ of the original scale was 0.84 , while it was 0.85 in the study of Gwak [18] and 0.80 in this study.

\section{3) Hospice care needs}

A tool developed by Kang et al. [19] and revised and updated by Gwak [18] was used.

This tool consisted of 23 items in four areas: five items for physical needs, five items for spiritual needs, six items for psychological needs, and seven items for family support needs. Each item was rated on a 5-point Likert scale from "very much needed" (5 points) to "not needed" (1 point). High scores indicated high needs.

Cronbach's $\alpha$ of the original scale was 0.93 , while it was 0.91 in the study of Gwak [18] and 0.96 in this study.

\section{Data analysis}

The data collected in this study were analyzed according to the following steps using SPSS for Windows version 23.0 (IBM Corp., Armonk, NY, USA). 
A. The general characteristics of family members of patients in the ICU were analyzed using counts and percentages or means and standard deviations, as appropriate.

B. Attitudes toward death, perceptions of hospice care, and hospice care needs among family members of patients in the ICU were analyzed using means and standard deviations.

C. Differences in attitudes toward death, perceptions of hospice care, and hospice care needs according to the general characteristics of family members of patients in the ICU were analyzed using the independent sample $\mathrm{t}^{-}$test and one-way analysis of variance. A post hoc analysis was conducted using the Scheffé test.

D. The associations among attitudes toward death, perceptions of hospice care, and hospice care needs reported by family members of patients in the ICU were analyzed using Pearson correlation coefficients.

\section{RESULTS}

\section{General characteristics of participants}

Fifty-one participants (44.7\%) were men, and 63 (55.3\%) were women. Their average age was 47.26 years. The greatest number of participants was in the 50 59 age group (32; $28.1 \%$ ), followed by the $40 \sim 49$ age group $(31 ; 27.2 \%)$, the under 40 age group (30; 26.3\%), and the over 60 age group (21; 18.4\%). Seventy participants $(61.4 \%)$ were the patients' children, 17 (14.9\%) were spouses, 17 (14.9\%) were siblings, and $10(8.8 \%)$ were parents. Eighty-two participants (71.9\%) were married, while 32 (28.1\%) were not. Sixty-three participants (55.3\%) were religious, while 51 were agnostic (44.7\%). Sixty-two participants (54.4\%) had a university education or above, while 52 (45.6\%) had a high-school education or below. Seventy-eight participants (68.4\%) were employed, while $36(31.6 \%)$ were not. Eighty-three (72.8\%) thought that their economic status was average, $18(15.8 \%)$ thought that it was poor, and $13(11.4 \%)$ thought that it was affluent (Table 1).

\section{Participants' attitudes toward death}

The average score for attitudes toward death among participants was $2.54 \pm 0.49$ out of 4 . The item with the highest score was "The idea of life after death bothers me greatly" (3.01 \pm
0.95), and the item with the lowest score was "I am not afraid of suffering for a long time until I die” (1.84 \pm 1.05$)$ (Table 2).

\section{Participants' perceptions of hospice care}

The average score for participants' perceptions of hospice care was $3.11 \pm 0.33$ out of 4 . The highest score for any of the five sub-areas was found for definitions and philosophy, followed in order by need for awareness-raising and education, care services, psychology and ethics, and recipients of care.

The item with the highest score in the definitions and philosophy sub-area was "Hospice care improves the quality of life by supporting those in the final stages of disease to live as comfortably as possible" $(3.39 \pm 0.67)$, and the item with the lowest score was "Hospice care prevents unnecessary prolongation of life" (2.93 \pm 0.76$)$.

In the recipients of care section, the highest average score was found for "The recipients of hospice care are patients and their families" (3.07 \pm 0.52$)$.

The item with the highest score in the care services section was "Helping to make the rest of life meaningful by providing accurate information and diagnosis" (3.37 \pm 0.66$)$, and the item

Table 1. Participants' General Characteristics ( $N=114)$.

\begin{tabular}{|c|c|c|c|c|}
\hline Variables & Categories & $\mathrm{n}$ & $\%$ & Mean $\pm S D$ \\
\hline \multirow[t]{2}{*}{ Sex } & Male & 51 & 44.7 & \\
\hline & Female & 63 & 55.3 & \\
\hline \multirow[t]{4}{*}{ Age (yr) } & $\leq 39$ & 30 & 26.3 & $47.26 \pm 12.57$ \\
\hline & $40 \sim 49$ & 31 & 27.2 & \\
\hline & $50 \sim 59$ & 32 & 28.1 & \\
\hline & $\geq 60$ & 21 & 18.4 & \\
\hline \multirow{4}{*}{$\begin{array}{l}\text { Relationship to } \\
\text { patient }\end{array}$} & Child & 70 & 61.4 & \\
\hline & Spouse & 17 & 14.9 & \\
\hline & Sibling & 17 & 14.9 & \\
\hline & Parent & 10 & 8.8 & \\
\hline \multirow[t]{2}{*}{ Marital status } & Married & 82 & 71.9 & \\
\hline & Not married & 32 & 28.1 & \\
\hline \multirow[t]{2}{*}{ Religion } & Yes & 63 & 55.3 & \\
\hline & None & 51 & 44.7 & \\
\hline \multirow[t]{2}{*}{ Education } & Above college & 62 & 54.4 & \\
\hline & $\begin{array}{l}\text { Less than high } \\
\text { school }\end{array}$ & 52 & 45.6 & \\
\hline \multirow[t]{2}{*}{ Employment status } & Employed & 78 & 68.4 & \\
\hline & Unemployed & 36 & 31.6 & \\
\hline \multirow[t]{3}{*}{ Financial status } & Affluent & 13 & 11.4 & \\
\hline & Average & 83 & 72.8 & \\
\hline & Poor & 18 & 15.8 & \\
\hline
\end{tabular}


Table 2. Attitudes towards Death ( $\mathrm{N}=114)$.

\begin{tabular}{|c|c|}
\hline Item & Mean \pm SD \\
\hline The idea of life after death bothers me greatly & $3.01 \pm 0.95$ \\
\hline $\begin{array}{l}\text { It makes me upset to think of my body decaying in the } \\
\text { grave }\end{array}$ & $2.89 \pm 1.05$ \\
\hline I am worried about what will happen in the afterlife & $2.89 \pm 1.01$ \\
\hline $\begin{array}{l}\text { It troubles me to think that I will miss out on so many } \\
\text { things which will happen after I die }\end{array}$ & $2.83 \pm 1.00$ \\
\hline Iam anxious when I see a coffin & $2.81 \pm 0.96$ \\
\hline I am very interested in the existence of an afterlife & $2.80 \pm 1.03$ \\
\hline $\begin{array}{l}\text { I dislike thinking that I won't be able to do anything myself } \\
\text { after I die }\end{array}$ & $2.75 \pm 1.05$ \\
\hline $\begin{array}{l}\text { I hate that I will get stuck and won't be able to do anything } \\
\text { when I die }\end{array}$ & $2.73 \pm 1.15$ \\
\hline I am perplexed that I will not be able to think after death & $2.72 \pm 1.13$ \\
\hline $\begin{array}{l}\text { The idea that death completely isolates me from everything } \\
\text { is perplexing }\end{array}$ & $2.72 \pm 1.09$ \\
\hline $\begin{array}{l}\text { The fact that I don't know anything about the afterlife } \\
\text { bothers me }\end{array}$ & $2.70 \pm 1.04$ \\
\hline It disturbs me to think that I can feel nothing after death & $2.70 \pm 1.03$ \\
\hline $\begin{array}{l}\text { I don't worry about being unable to do anything after } \\
\text { death* }\end{array}$ & $2.61 \pm 1.00$ \\
\hline I will leave detailed instructions on what to do after I die* & $2.61 \pm 0.91$ \\
\hline I don’t care what happens to my body after I die** & $2.60 \pm 0.90$ \\
\hline I don't want to think that I can't do anything after I die & $2.54 \pm 1.06$ \\
\hline $\begin{array}{l}\text { I don't think much about dying and being placed in the } \\
\text { coffin* }\end{array}$ & $2.53 \pm 1.02$ \\
\hline I don't worry about how others will treat my body after I die & $2.46 \pm 1.02$ \\
\hline $\begin{array}{l}\text { I never worry about what will happen to my body after } \\
\text { my funeral* }\end{array}$ & $2.45 \pm 1.03$ \\
\hline I am looking forward to a new life after death* & $2.21 \pm 1.04$ \\
\hline I don't want to even think about having surgery & $2.07 \pm 0.95$ \\
\hline $\begin{array}{l}\text { Iam afraid of (psychological) suffering at the moment } \\
\text { of death }\end{array}$ & $2.07 \pm 0.94$ \\
\hline $\begin{array}{l}\text { Iam not particularly afraid even if I think about } \\
\text { having cancer }\end{array}$ & $2.06 \pm 1.02$ \\
\hline I am afraid I will experience pain at the moment of death & $2.01 \pm 0.96$ \\
\hline I am not afraid of suffering for a long time until I die* & $1.84 \pm 1.05$ \\
\hline Attitudes towards death & $2.54 \pm 0.49$ \\
\hline
\end{tabular}

*Reverse questions.

with the lowest score was "Only medical staff such as doctors and nurses work in the hospice care ward" $(2.68 \pm 0.74)$.

The item with the highest score in the psychology and ethics section was "Terminally ill patients often experience frequent emotional changes while embracing death" (3.34 \pm 0.66$)$, and the item with the lowest score was "It is meaningless to provide life-prolonging treatment for terminally ill patients" (2.91 \pm 0.85 ).

In the section dealing with needs for awareness-raising and education, the item "A public awareness campaign and education on hospice care are needed" received a high average score (3.30 \pm 0.66$)$ (Table 3).

\section{Hospice care needs among participants}

Participants' average score for hospice care needs was 3.99 \pm 0.67 out of 5 . Of the four sub-areas, the highest average score was found for psychological needs, followed in order by physical needs, family support needs, and spiritual needs.

The item with the highest score in the physical needs section was "Minimize pain with palliative care" $(4.26 \pm 0.84)$, and the item with the lowest score was "Help with insomnia"(3.97 \pm 0.95).

In the spiritual needs section, the item with the highest score was "Provide answers when patients want to know about the nature of death" $(3.88 \pm 0.95)$, and the item with the lowest score was "Arrange meetings with religious leaders (pastors, priests, monks)" (3.46 \pm 1.14$)$.

The item with the highest score in the psychological needs section was "Allow patients to be with the people they choose" (4.25 \pm 0.86$)$, and the item with the lowest score was "Create an environment where patients can express emotions (anger, anxiety, sadness)" (3.98 \pm 0.97$)$.

The item with the highest score for family support needs was "Hospice care should be available continuously" (4.16 \pm 0.86$)$, and the item with the lowest score was "Care for patients through home visits to help the family" (3.71 \pm 1.09$)$ (Table 4).

\section{Differences in attitudes toward death, percep- tions of hospice care, and hospice care needs ac- cording to participants' general characteristics}

There were no significant differences in attitudes toward death according to participants' general characteristics such as sex, age, relationship with the patient, marital status, religion, education, occupation, or economic status (Table 5).

Significant differences were found in perceptions of hospice care according to participants' age $(\mathrm{F}=3.06, \mathrm{P}=0.031)$ and marital status $(t=3.55, \mathrm{P}=0.001)$. According to the results of the post hoc test, higher perceptions of hospice care were found in the 50 59 age group than in the under 40 age group. The average score for perceptions of hospice care was higher among married participants than among single partici- 
Table 3. Perceptions of Hospice Care ( $\mathrm{N}=114)$.

\begin{tabular}{|c|c|c|}
\hline & Item & Mean \pm SD \\
\hline \multirow[t]{5}{*}{ Definitions/ philosophy } & $\begin{array}{l}\text { Hospice care improves the quality of life by supporting those in the final stages of disease to } \\
\text { live as comfortably as possible }\end{array}$ & $3.39 \pm 0.67$ \\
\hline & Hospice care helps to organize affairs during life while maintaining the dignity of patients & $3.24 \pm 0.64$ \\
\hline & Hospice care helps to accept death as part of the normal course of life & $3.07 \pm 0.63$ \\
\hline & Hospice care prevents unnecessary prolongation of life & $2.93 \pm 0.76$ \\
\hline & Subtotal & $3.16 \pm 0.45$ \\
\hline \multirow[t]{3}{*}{ Recipients of care } & The recipients of hospice care are patients and their families & $3.31 \pm 0.73$ \\
\hline & An adequate period of hospice care is approximately 3 to 6 months before death & $2.84 \pm 0.72$ \\
\hline & Subtotal & $3.07 \pm 0.52$ \\
\hline \multirow[t]{9}{*}{ Care services } & Helping to make the rest of life meaningful by providing accurate information and diagnosis & $3.37 \pm 0.66$ \\
\hline & Hospice care at home is needed in addition to inpatient wards & $3.30 \pm 0.61$ \\
\hline & Hospice care is a great help for patients and their families & $3.26 \pm 0.57$ \\
\hline & Hospice care is the combined effort of relieving the patients' physical, mental, and spiritual pain & $3.23 \pm 0.72$ \\
\hline & Teams from different treatment areas work together at the hospice care ward & $3.15 \pm 0.67$ \\
\hline & Hospice care relieves the financial burden on patients and their family & $2.96 \pm 0.79$ \\
\hline & Prayer and spiritual support are enough* & $2.78 \pm 0.94$ \\
\hline & Only medical staff such as doctors and nurses work in the hospice care ward* & $2.68 \pm 0.74$ \\
\hline & Subtotal & $3.09 \pm 0.34$ \\
\hline \multirow[t]{5}{*}{ Psychology and ethics } & Terminally ill patients often experience frequent emotional changes while embracing death & $3.34 \pm 0.66$ \\
\hline & Hospice care helps families overcome loss and sadness by embracing patients' deaths & $3.14 \pm 0.62$ \\
\hline & It is unethical to have terminally ill patients die in the ICU or treatment room & $2.96 \pm 0.83$ \\
\hline & It is meaningless to provide life-prolonging treatment for terminally ill patients & $2.91 \pm 0.85$ \\
\hline & Subtotal & $3.09 \pm 0.49$ \\
\hline \multirow{4}{*}{$\begin{array}{l}\text { Need for awareness-raising } \\
\text { and education }\end{array}$} & A public awareness campaign and education on hospice care are needed & $3.30 \pm 0.66$ \\
\hline & I would strongly recommend hospice care to a patient in need & $2.97 \pm 0.73$ \\
\hline & Subtotal & $3.13 \pm 0.61$ \\
\hline & Total & $3.11 \pm 0.33$ \\
\hline
\end{tabular}

*Reverse question.

pants.

Hospice care needs did not significantly differ according to participants' general characteristics, such as sex, age, relationship with the patient, marital status, religion, education, occupation, and economic status (Table 5).

\section{Associations among attitudes toward death, per- ceptions of hospice care, and hospice care needs as reported by family members of patients in the ICU}

The analysis of the associations among attitudes toward death, perceptions of hospice care, and hospice care needs in family members of patients in the ICU demonstrated a significant positive association between perceptions of hospice care and hospice care needs $(r=0.49, \mathrm{P}<0.001)$. A positive association was found between attitudes toward death and percep- tions of hospice care, but this association was not statistically significant $(r=0.18, P<0.058)$. Attitudes toward death and hospice care needs also had a positive association that was not statistically significant (Table 6).

\section{DISCUSSION}

This study was conducted to provide preliminary data that can facilitate the delivery of high-quality hospice and palliative care at appropriate moments in the ICU, a topic of recent interest, by exploring attitudes toward death, perceptions of hospice care, and hospice care needs among family members of patients who were receiving care in the Dong-A University Hospital ICU.

The average score for attitudes toward death in this study was 2.54 out of 4 , which is similar to the results reported by 
Table 4. Needs for Hospice Care ( $\mathrm{N}=114)$.

\begin{tabular}{|c|c|c|}
\hline & Items & Mean $\pm S D$ \\
\hline \multirow[t]{6}{*}{ Physical needs } & Minimize pain with palliative care & $4.26 \pm 0.84$ \\
\hline & Prevent/care for skin damage (bedsores) & $4.15 \pm 0.90$ \\
\hline & Help with defecation (constipation, diarrhea) & $4.04 \pm 0.91$ \\
\hline & Help with problems related to nutrition and loss of appetite & $3.99 \pm 0.90$ \\
\hline & Help with insomnia & $3.97 \pm 0.95$ \\
\hline & Subtotal & $4.08 \pm 0.75$ \\
\hline \multirow[t]{6}{*}{ Spiritual needs } & Provide answers when patients want to know about the nature of death & $3.88 \pm 0.95$ \\
\hline & Help them discover the meaning and purpose of life & $3.82 \pm 1.01$ \\
\hline & Pray for the family and patients & $3.65 \pm 1.03$ \\
\hline & Allow patients to own religious books or objects & $3.57 \pm 1.02$ \\
\hline & Arrange meetings with religious leaders (pastors, priests, monks) & $3.46 \pm 1.14$ \\
\hline & Subtotal & $3.68 \pm 0.82$ \\
\hline \multirow[t]{7}{*}{ Psychological needs } & Allow patients to be with the people they choose & $4.25 \pm 0.86$ \\
\hline & Emotional support when the patient is anxious & $4.22 \pm 0.87$ \\
\hline & Allow patients to talk about everything on their mind & $4.19 \pm 0.87$ \\
\hline & Spend as much time as possible with patients & $4.17 \pm 0.87$ \\
\hline & Help patients do what they wish to do & $4.11 \pm 0.91$ \\
\hline & Create an environment where patients can express emotions (anger, anxiety, sadness) & $3.98 \pm 0.97$ \\
\hline & Subtotal & $4.15 \pm 0.73$ \\
\hline \multirow[t]{9}{*}{ Family support needs } & Hospice care should be available continuously & $4.16 \pm 0.86$ \\
\hline & Help family cope with grief and loss after the patient's death & $4.09 \pm 0.95$ \\
\hline & Provide patients' family with information about funeral arrangements & $4.08 \pm 0.91$ \\
\hline & Provide patients' family with information on financial aid and local community resources & $4.05 \pm 0.99$ \\
\hline & Listen to the difficulties that the family has & $4.01 \pm 0.93$ \\
\hline & $\begin{array}{l}\text { Provide support, encouragement, and counseling if the family is criticized for giving up on active } \\
\text { treatment for the patient }\end{array}$ & $3.99 \pm 0.84$ \\
\hline & Care for patients through home visits to help the family & $3.71 \pm 1.09$ \\
\hline & Subtotal & $4.01 \pm 0.76$ \\
\hline & Total & $3.99 \pm 0.67$ \\
\hline
\end{tabular}

Oh [20] and Jun [21], in studies conducted among nurses. However, this score is lower than that reported by Yoo [15] among hospice volunteers. Hospice volunteers had positive attitudes toward death as a result of their serious reflections on death prompted by education and experiences of hospice care [15]. The reason nurses had a more negative attitude toward death than hospice volunteers may be that despite their education and practical clinical experience, they lack time to seriously reflect on death due to their heavy workload [15]. Therefore, in order to foster a positive attitude toward death, education on death and experiences related to death are important. However, since experiences related to death are limited and not easily obtained, in order for family members of patients in the ICU to foster a positive attitude toward death and to make the right decisions for the patient, they should receive appropriate education about death.

The item that had the highest score for attitudes toward death was "The idea of life after death bothers me greatly." This finding is consistent with those reported by Oh [20] and Jun [21] among nurses. These results indicate that family members of ICU patients and nurses think about death in the present moment, rather than in terms of the afterlife. However, not worrying about life after death does not indicate a positive attitude toward death. In this study, the item "I am looking forward to a new life after death" had an average score of 2.21, which was relatively low. By comparing the results of these two items, it can be inferred that the reason why participants did not worry about the afterlife was not that they were looking forward to a new life after death. Family members of patients in the ICU seemed only to deal with the situation 
Table 5. Attitudes towards Death, Perceptions and Needs for Hospice Care by Participants' General Characteristics (N=114).

\begin{tabular}{|c|c|c|c|c|c|c|c|c|c|c|}
\hline \multirow{3}{*}{ Variables } & \multirow{3}{*}{ Categories } & \multicolumn{3}{|c|}{ Attitudes towards death } & \multicolumn{3}{|c|}{ Perceptions of hospice care } & \multicolumn{3}{|c|}{ Needs for hospice care } \\
\hline & & \multirow{2}{*}{ Mean \pm SD } & \multirow{2}{*}{$\mathrm{t} / \mathrm{F}$} & \multirow{2}{*}{$\frac{P}{\text { Scheffé }}$} & \multirow{2}{*}{ Mean $\pm S D$} & \multirow{2}{*}{$\mathrm{t} / \mathrm{F}$} & \multirow{2}{*}{$\frac{P}{\text { Scheffé }}$} & \multirow{2}{*}{ Mean \pm SD } & \multirow{2}{*}{$t / F$} & \multirow{2}{*}{$\frac{P}{\text { Scheffé }}$} \\
\hline & & & & & & & & & & \\
\hline \multirow[t]{2}{*}{ Sex } & Male & $2.53 \pm 0.47$ & -0.19 & 0.846 & $3.06 \pm 0.31$ & -1.32 & 0.188 & $3.97 \pm 0.65$ & -0.31 & 0.759 \\
\hline & Female & $2.55 \pm 0.52$ & & & $3.14 \pm 0.34$ & & & $4.01 \pm 0.68$ & & \\
\hline \multirow[t]{4}{*}{ Age (yr) } & $\leq 39^{\mathrm{a}}$ & $2.49 \pm 0.51$ & 1.51 & 0.217 & $2.99 \pm 0.33$ & 3.06 & $0.031 *$ & $3.99 \pm 0.58$ & 0.57 & 0.633 \\
\hline & $40 \sim 49^{b}$ & $2.42 \pm 0.53$ & & & $3.09 \pm 0.31$ & & $c>a$ & $4.01 \pm 0.78$ & & \\
\hline & $50 \sim 59^{c}$ & $2.62 \pm 0.52$ & & & $3.23 \pm 0.30$ & & & $4.07 \pm 0.71$ & & \\
\hline & $\geq 60^{d}$ & $2.68 \pm 0.32$ & & & $3.11 \pm 0.33$ & & & $3.83 \pm 0.55$ & & \\
\hline \multirow{4}{*}{$\begin{array}{l}\text { Relationship to } \\
\text { patient }\end{array}$} & Child & $2.50 \pm 0.54$ & 1.55 & 0.205 & $3.07 \pm 0.34$ & 0.81 & 0.492 & $3.97 \pm 0.69$ & 0.29 & 0.833 \\
\hline & Spouse & $2.71 \pm 0.34$ & & & $3.15 \pm 0.39$ & & & $3.99 \pm 0.62$ & & \\
\hline & Sibling & $2.46 \pm 0.43$ & & & $3.20 \pm 0.25$ & & & $3.95 \pm 0.68$ & & \\
\hline & Parent & $2.74 \pm 0.39$ & & & $3.12 \pm 0.23$ & & & $4.18 \pm 0.67$ & & \\
\hline \multirow[t]{2}{*}{ Marital status } & Married & $2.59 \pm 0.49$ & 1.67 & 0.098 & $3.17 \pm 0.31$ & 3.55 & $0.001 *$ & $4.02 \pm 0.70$ & 0.62 & 0.539 \\
\hline & Not married & $2.42 \pm 0.49$ & & & $2.94 \pm 0.30$ & & & $3.93 \pm 0.59$ & & \\
\hline \multirow[t]{2}{*}{ Religion } & Yes & $2.55 \pm 0.54$ & 0.04 & 0.967 & $3.10 \pm 0.31$ & -0.08 & 0.993 & $4.00 \pm 0.67$ & 0.15 & 0.881 \\
\hline & No & $2.54 \pm 0.43$ & & & $3.10 \pm 0.35$ & & & $3.98 \pm 0.67$ & & \\
\hline \multirow[t]{2}{*}{ Education } & Above college & $2.54 \pm 0.50$ & -0.16 & 0.872 & $3.13 \pm 0.35$ & 0.96 & 0.332 & $4.00 \pm 0.71$ & 0.15 & 0.885 \\
\hline & $\begin{array}{l}\text { Less than high } \\
\text { school }\end{array}$ & $2.55 \pm 0.49$ & & & $3.07 \pm 0.30$ & & & $3.98 \pm 0.62$ & & \\
\hline \multirow[t]{2}{*}{ Employment status } & Employed & $2.58 \pm 0.49$ & 0.92 & 0.359 & $3.12 \pm 0.33$ & 0.76 & 0.448 & $4.02 \pm 0.66$ & 0.68 & 0.497 \\
\hline & Unemployed & $2.48 \pm 0.50$ & & & $3.07 \pm 0.32$ & & & $3.93 \pm 0.68$ & & \\
\hline \multirow[t]{3}{*}{ Financial status } & Affluent & $2.60 \pm 0.64$ & 0.21 & 0.812 & $3.07 \pm 0.49$ & 0.56 & 0.573 & $4.11 \pm 0.83$ & 1.88 & 0.158 \\
\hline & Average & $2.55 \pm 0.44$ & & & $3.10 \pm 0.30$ & & & $3.92 \pm 0.65$ & & \\
\hline & Poor & $2.48 \pm 0.62$ & & & $3.18 \pm 0.30$ & & & $4.23 \pm 0.61$ & & \\
\hline
\end{tabular}

*Reverse question.

that they faced directly, rather than reflecting on death seriously, due to the psychological, social, and economic problems prompted by the abrupt change of status of patients in the ICU. Among the items about attitudes toward death, the item "I am not afraid of suffering for a long time until I die" had the lowest score. Although family members of ICU patients are not likely to have experienced death directly, they face the issue of death through their family member being admitted to the ICU. Therefore, abstract fears and concerns about death could have manifested as worries regarding the length of time and level of pain until death [22].

Participant's average score for perceptions of hospice care was 3.11 out of 4, which is similar to the results of Choi [23], who conducted a study of adults in the general population. The ICU admits both non-cancer and cancer patients; therefore, many family members of ICU patients would not have been interested in hospice and palliative care before their family member was admitted to the ICU, which may explain why
Table 6. Correlations among Attitudes towards Death, Perceptions, and Needs for Hospice Care ( $\mathrm{N}=114)$.

\begin{tabular}{|c|c|c|}
\hline & $\begin{array}{l}\text { Attitudes towards } \\
\text { death }\end{array}$ & $\begin{array}{l}\text { Perceptions of } \\
\text { hospice care }\end{array}$ \\
\hline & $r(P)$ & $r(P)$ \\
\hline Perceptions of hospice care & $0.18(0.058)$ & \\
\hline Needs for hospice care & $0.03(0.763)$ & $0.49(<0.001)$ \\
\hline
\end{tabular}

the results of the present study are similar to those of adults in the general population. However, the average score found in our study is lower than that reported in Jun [21], who studied nurses, Kim [24], who studied adult participants in a hospice volunteer education program, and Gwak [18], who conducted a study of cancer patients and their family members. Nurses and adults who participated in a hospice volunteer education program had higher scores for perceptions of hospice care because they had many opportunities to directly experience hospice and palliative care and to receive education. More- 
over, hospice and palliative care policies was implemented along with the 2003 law on cancer management, which led to regional cancer centers delivering various education and awareness-raising initiatives [25]. Accordingly, the possibility of cancer patients and their family members being direct recipients of hospice and palliative care became higher and more opportunities arose to be exposed to awareness-raising and educational initiatives; this is likely to have spurred improvements in perceptions of hospice care.

Therefore, in order to enhance perceptions of hospice care among the family members of patients in the ICU, it is necessary to expand education and awareness-raising initiatives on hospice and palliative care to encompass a broader variety of modalities than in the status quo. When the scores were evaluated by sub-area, the highest score was found in the definitions and philosophy of hospice care and the lowest score was found for the recipients of care. In most previous studies, the scores for the psychology and ethics of hospice care were low $[18,21]$, but in this study, the lowest score was found in the recipients of care sub-area. Among the items in the recipients of care sub-area, the lowest score was found for the item "An adequate period of hospice care is approximately 3 to 6 months before death," which suggests that accurate information or judgement about hospice and palliative care is lacking. The item with the lowest score in perceptions of hospice care was "Only medical staff such as doctors and nurses work in the hospice care ward." It may be speculated that participants recognized the term "medical" as only pertaining to doctors and nurses due to their lack of knowledge about hospice and palliative care. The item with the highest score was "Hospice care improves the quality of life by supporting those in the final stages of disease to live as comfortably as possible," which indicates that this item reflects what family members of ICU patients need the most from hospice and palliative care.

Hospice care needs among participants had an average score of 3.99 out of 5. In previous studies that used the same scale, the score for hospice care needs among family members of cancer patients was 3.67 in the study of Son and Park [9] conducted in 2015, and 4.45 in the study of Gwak [18] conducted in 2017. These results show that hospice care need increased over time in general. However, the fact that the average score in this study, which was conducted in 2019, is lower than the scores reported by Son and Park [9] and Gwak [18] could be that patients in the ICU are not limited to cancer patients. The Act on Decisions on Life-Sustaining Treatment implemented in 2018 included patients with some non-cancer diseases, as well as cancer patients, to those considered terminally ill.

Therefore, although this study examined the hospice care needs of family members of patients in the ICU, it seems necessary to study the hospice care needs of non-cancer patients more specifically in the future. When the four sub-areas were examined, psychological needs had the highest score in this study (4.15), but Gwak [18], who analyzed cancer patients and their family members, and Jin [26], who conducted a study among community members, found the highest scores for physical needs. However, in the study of Son and Park [9], unlike in the study of Gwak [18], family members of cancer patients reported the greatest needs for psychological care, which is similar to the results of this study. It is speculated that family members of ICU patients think that patients' physical needs are sufficiently met in the specialized environment of the ICU, while the limitations in visitation and difficulties in communicating with medical staff may be reflected in psychological needs for care.

No meaningful differences were found in attitudes toward death according to general characteristics. Significant differences were expected according to religion or the type of disease of the patient in the ICU, but no such differences were found. These null findings might have been found because this study did not consider the duration of disease of the patient in the ICU, the duration of hospitalization in the ICU, or the psychological, social, and spiritual characteristics of participants. Therefore, attitudes toward death among family members of patients in the ICU should be analyzed again in the future based on a careful consideration of these factors.

Meaningful differences were found in perceptions of hospice care according to participants' age and marital status. This result is similar to the findings in Gwak [18] for the family members of cancer patients. However, while the average score was higher in the 20 39 age group compared to the 40 59 and 60 and above age groups in the results reported by Gwak [18], in the present study, the perceptions of hospice care were higher in the 50 59 age group than in the under 40 age group. Future research should carefully analyze factors 
other than participants being family members of patients in relation to differences in perceptions of hospice and palliative care. Moreover, this study found that married participants had higher average scores for perceptions of hospice care than unmarried participants. Ko and Kim [27], who analyzed family members of inpatients, found that marital status did not significantly influence perceptions of hospice care, and Kim [28], who conducted a study among family members of latestage cancer patients, reported that perceptions of hospice care were significantly different according to family composition. Therefore, a follow-up study examining which factors influence perceptions of hospice care depending on the disease of the patient in the ICU and the participants' family status in more detail is warranted.

Hospice care needs did not meaningfully differ by participants' general characteristics. In the study of Jin [26] among community members, hospice care needs were significantly higher among religious participants, and Son and Park [9], who conducted a study among family members of cancer patients, found significant differences depending on the patient's disease stage. Therefore, researchers should investigate which general characteristics influence hospice care needs among family members of patients in the ICU based on a more detailed categorization of the general characteristics of the family members.

When the associations among attitudes toward death, perceptions of hospice care, and hospice care needs were analyzed, a meaningful positive association was found between perceptions of hospice care and hospice care needs $(\mathrm{r}=0.49, \mathrm{P}<0.001)$. This finding is consistent with those of Ro et al. [29], who conducted a study among community members, and Gwak [18], who analyzed the family members of cancer patients. This finding suggests that proper perceptions of hospice care can lead to the recognition of hospice care needs at an appropriate time. Therefore, it is important to enhance perceptions of hospice care before individuals experience the crisis of a family member being admitted to the ICU.

In conclusion, in order for family members of patients in the ICU to have proper perceptions of hospice and palliative care and to make decisions for the family at the right moment, education about attitudes toward death, as well as about hospice and palliative care, for the general population should be further strengthened. The public's awareness of hospice and pal- liative care should be raised through various media initiatives. By raising awareness and providing education about advance directives and physician orders for life-sustaining treatment, which have been implemented through the Act on Decisions on Life-Sustaining Treatment since 2018, efforts should be made to reflect patients' preferences in decision-making for treatments including hospice and palliative care. Moreover, follow-up studies should aim to identify other factors that influence the hospice care needs of family members of ICU patients by stratifying them according to general characteristics not addressed in this study.

\section{CONFLICT OF INTEREST}

No potential conflict of interest relevant to this article was reported.

\section{ORCID}

Yunha Oak, https://orcid.org/0000-0002-0434-4770

Young-Sun Kim, https://orcid.org/0000-0001-6408-9516

\section{AUTHOR'S CONTRIBUTIONS}

Conceptualization: YO, YSK. Data curation: YO. Formal. Analysis: YO, YSK. Funding acquisition: None. Investigation: YO. Methodology: YO, YSK. Project administration: YO, YSK. Resources: YO, YSK. Software: YO, YSK. Supervision: YSK. Validation: YO. Visualization: YO. Writing - original draft: YO. Writing - review \& editing: YO, YSK.

\section{SUPPLEMENTARY MATERIALS}

Supplementary materials can be found via https://doi. org/10.14475/kjhpc.2020.23.4.172. 


\section{REFERENCES}

1. Lee YJ. Life-sustaining treatment in the intensive care unit. KATRD International Conference 2018; 2018 Nov 8-9; Seoul, Korea. Seoul: The Korea Academy of Tuberculosis and Respiratory Diseases; 2018.

2. Lustbader DR, Nelson JE, Weissman DE, Hays RM, Mosenthal AC, Mulkerin C, et al. Physician reimbursement for critical care services integrating palliative care for patients who are critically ill. Chest 2012;141:787-92.

3. Nelson JE, Brasel KJ, Campbell, ML, Cortez TB, Curtis JR, Lustbader, DR, et al. Evaluation of ICU palliative care quality: A technical assistance monograph from IPAL-ICU Project [Internet]. New York, N.Y.: The IPAL-ICU Project; Center to Advance Palliative Care; c2010 [cited 2019 Sept 20]. Available from: http://ipal.capc.org/downloads/ipal-icu-evaluation-of-icu-palliativecare- quality.pdf.

4. Kim HJ. Relationship between unmet needs and quality of life of family caregivers of cancer patients in Korea [master's thesis]. Seoul: Seoul National Univ.; 2014. Korean.

5. Monteiro F. Family reliance on physicians' decisions in life-sustaining treatments in acute-on-chronic respiratory diseases in a respiratory ICU: a single-center study. Respir Care 2014;59:411-9.

6. Davidson JE, Jones C, Bienvenu OJ. Family response to critical illness: post-intensive care syndrome-family. Crit Care Med 2012;40:618-24.

7. Thorson JA, Powell FC. Elements of death anxiety and meaning of death. J Clin Psychol 1988;44:691-701.

8. Nelson JE, Hope AA. Integration of palliative care in chronic critical illness management. Respir Care 2012;57:1004-12; discussion 1012-3.

9. Son YJ, Park YR. Perception on hospice, attitudes toward death and needs of hospice care between the patients with cancer and family. Korean J Rehabil Nurs 2015;18:11-9.

10. Romano AM, Gade KE, Nielsen G, Havard R, Harrison Jr JH, Barclay J, et al. Early palliative care reduces end-of-life intensive care unit (ICU) use but not ICU Course in patients with advanced cancer. Oncologist 2017;22:318-23.

11. Altaker KW, Howie-Esquivel J, Cataldo JK. Relationships among palliative care, ethical climate, empowerment, and moral distress in intensive care unit nurses. Am J Crit Care 2018;27:295-302.

12. Noome M, Beneken Genaamd Kolmer DM, van Leeuwen E, Dijkstra BM, Vloet LCM. The role of ICU nurses in the spiritual aspects of end-oflife care in the ICU: an explorative study. Scand J Caring Sci 2017;31:569-78.

13. Curtis JR, Downey L, Engelberg RA. The importance and challenge of measuring family experience with end-of-life care in the ICU. Intensive Care Med 2016;42:1179-81.

14. Park SC. A study on the death orientation of hospice Volunteers. J Korean Acad Nurs 1992;22:68-80.

15. Yoo MS. The influences of death attitudes and emotional intelligence on hospice volunteers' perception of life as meaningful. J Korean Acad Soc Home Care Nurs 2016;23:90-9.

16. Kim JH. The attitude of medical personnel about death and hospice research [master's thesis]. Seoul: Hanyang Univ.; 1990. Korean.

17. Lee EJ. A study of spot-survey towards the attitude of hospice [master's thesis]. Iksan: Wonkwang Univ.; 1998. Korean.

18. Gwak DY. Hospice palliative care perception and nursing demand of cancer patient's and families [master's thesis]. Busan: Catholic Univ. of Pusan; 2017. Korean.

19. Kang KA, Kim SJ, Kim YS. The need for hospice care in families of patients with cancer. J Korean Acad Community Health Nurs 2004;15:639-47.

20. Oh SJ. Nurse's anxiety from death, attitude to death and terminal care families [master's thesis]. Suwon: Ajou Univ.; 2016. Korean.

21. Jun JS. Spiritual well-being, attitude towards death and perception of hospice care among nurses [master's thesis]. Busan: Catholic Univ. of Pusan: 2014. Korean.

22. Hong EM, Jun MD, Park ES, Ryu EJ. Death perceptions, death anxiety, and attitudes to death in oncology nurses. Asian Oncol Nurs 2013;13:265-72.

23. Choi KA. Perception of hospice and attitude to death of the adults in a local area [master's thesis]. Busan: Kosin Univ.; 2011. Korean.

24. Kim MS. Comparison on the perception about hospice and the meaning of life of participants and non-participants of the hospice volunteer education program [master's thesis]. Gwangju: Chonnam National Univ.; 2007. Korean.

25. Ministry of Health and Welfare [Internet]. Hospice and palliative care. Sejong: Ministry of Health and Welfare; 2019 [cited 2019 Aug 9]. Available from: http://www.mohw.go.kr/react/al/sal0301vw.jsp?PAR_MENU_ID=04\&MENU_ID=0403\&CONT_SEQ=347917.

26. Jin HJ. Need for hospice care in Busan area [master's thesis]. Busan: Kosin Univ.; 2008. Korean.

27. Ko SH, Kim HK. The knowledge and needs of hospice for inpatients' family. Korean J Hosp Palliat Care 2005;8:131-42.

28. Kim H. A study on the attitudes of families with a terminal cancer patient to hospice [master's thesis]. Iksan: Wonkwang Univ.; 2005. Korean.

29. Ro YJ, Han SS, Ahn SH, Yong JS. Community residents' knowledge, attitude, and needs for hospice care. Korean J Hosp Palliat Care 1999;2:23-35. 